\title{
INDIRECT CAUSES OF MATERNAL DEATH- AN AUTOPSY STUDY
}

\author{
Zachariah Thomas ${ }^{1}$
}

1Professor, Department of Forensic Medicine, Government Medical College, Idukki, Kerala, India.

\section{BACKGROUND}

\section{ABSTRACT}

Autopsy is an important tool in the investigation of maternal death. It provides valuable information about pathophysiological changes in various organs, which may be important in the delineation of the sequence of events leading to maternal death. The present study was conducted at Department of Forensic Medicine at Government Medical College, Thiruvananthapuram, Kerala during 1995 January to April 2003. The circumstances which lead to medico-legal autopsy were cases either brought dead to casualty, referred cases due to obstetrical complications from distant hospitals and allegations of medical negligence in the care and management by relatives which later turned into a medico-legal case.

The objectives of the study are:

1. To detect the spectrum of causes leading to maternal death cases subjected to medico-legal autopsy.

2. To identify the indirect, late and fortuitous causes of maternal deaths.

3. To suggest measures to prevent maternal deaths.

\section{MATERIALS AND METHODS}

Sixty-five cases brought for medico-legal autopsy during the period from January 1995 to April 2003 were included in the present retrospective/ prospective study.

\section{RESULTS}

In the present study, direct maternal deaths were the leading cause in 39 cases (60\%), among them postpartum haemorrhage was the prime cause of death i.e. 15 cases (23\%), 24 cases (37\%) were due to indirect causes and 2 cases (3\%) were fortuitous dea ths. Even though death following obstetric haemorrhage remained the prime direct cause, indirect causes of maternal deaths were valvular heart disease, intracranial pathology, hepatic and pulmonary disease complicating pregnancy.

\section{CONCLUSION}

A detailed autopsy examination supplemented with all necessary investigations can reveal many obscure causes, as it was found in the present autopsy study. A multidisciplinary approach with regular audit and mortality conferences on maternal deaths will help to identify the causes and to prevent maternal deaths. Though the risk of death from complications of pregnancy has decreased during the past few decades in India, it continues to remain higher in other developing countries.

\section{KEY WORDS}

Maternal Deaths, Direct Maternal Deaths, Indirect Maternal Deaths, Medico-Legal Autopsy.

HOW TO CITE THIS ARTICLE: Thomas Z. Indirect causes of maternal death- an autopsy study. J. Evolution Med. Dent. Sci. 2018;7(38):4240-4244, DOI: $10.14260 /$ jemds/2018/946

\section{BACKGROUND}

According to World Health Organization (WHO), "A maternal death is defined as death of a woman while pregnant or within 42 days of termination of pregnancy, irrespective of the duration and site of pregnancy from any cause related to or aggravated by pregnancy or its management, but not from accidental or incidental causes" (ICD-10). ${ }^{1}$

\section{Maternal Deaths can be classified into Four Broad Groups $^{2}$}

1. Direct Maternal Deaths: Death resulting from obstetric complications of the pregnant state (pregnancy, labour and the puerperium) from interventions, omissions, incorrect treatment or from chain of events resulting from any of the above.

'Financial or Other Competing Interest': None.

Submission 04-08-2018, Peer Review 30-08-2018,

Acceptance 07-09-2018, Published 17-09-2018.

Corresponding Author:

Dr. Zachariah Thomas,

Government T. D. Medical College,

Alappuzha, Kerala, India.

E-mail:zachtom24@yahoo.com

DOI: $10.14260 /$ jemds $/ 2018 / 946$
2. Indirect Maternal Deaths: Death resulting from previous existing disease or disease that developed during pregnancy and which was not due to direct obstetric causes, but which was aggravated by physiological effects of pregnancy.

3. Late Death: Death occurring between 42 days and one year after abortion, miscarriage or delivery that are due to direct and fortuitous maternal causes.

4. Fortuitous Deaths: Death from unrelated causes, which happen to occur in pregnancy or puerperium; Eg. Accidental or unnatural death.

The Maternal Mortality Rate (MMR) is the annual number of female deaths per 100,000 live births from any cause related to or aggravated by pregnancy or its management (excluding accidental or incidental causes). ${ }^{3}$ Maternal mortality reflects the quality of obstetric care in a community. To achieve better mother and child health, the health care services must be accessible to all and should be utilised in a judicious manner.

Almost half a million women die every year from complications during pregnancy and child birth. Everyday, approximately 830 women die from preventable causes related to pregnancy and child birth. About $99 \%$ of these 
women are from developing world, concentrated in Africa and Asia. Top countries where maternal mortality is less than ten are Austria, Sweden, Japan, Spain, Switzerland, Israel, Kuwait, Poland, Iceland, Greece etc.

The maternal mortality ratio has reduced in India from 254 in 2004 - 2006 to 212 in $2007-2009$ and to 178 in 2010 - 2012 and 167/100,000 live births in 2011 - 2013 Kerala's health indicators have been consistently better than National Indian average due to high literacy, better road networks and a large number of health facilities. However, MMR in Kerala has remained almost static in the last couple of decades. The sample registration system reported the MMR for Kerala in the period $2004-06$ as 95, $2007-2009$ as 81, $2010-12$ as 66 and 2011 - 13 as 61 per 100,000 live births. (Source sample registration system Registrar General of India).

In the United Kingdom, these categories of death are notified through UK Confidential Enquiry into Maternal Deaths (CEMD), which started in one region in 1921 and became nationwide in 1951, collates all information and reports them every three years. The purpose of the confidential enquiry is not simply to establish a basic cause of death, but to reach an understanding as far as possible of all the circumstances surrounding it. The Kerala Federation of Obstetrician and Gynaecology (KFOG) choose to conduct a Confidential Enquiry into Maternal Deaths in tune with UK CEMD from $2004 .^{4}$

There is global lack of autopsy related data leading to the circumstances of maternal deaths in developing countries. Most deliveries and deaths occur in rural areas, where there are no facilities in hospitals to tackle obstetric emergency or lack of obstetricians and proper transport system. Autopsy is an important tool in the investigation of maternal death. It provides valuable information about pathophysiological changes in various organs, which may be important in the delineation of the sequence of events leading to maternal death. The outcome requires clinical data, pathological and microbiological investigation, information from investigation officer and relatives.

\section{MATERIALS AND METHODS}

The descriptive study of sixty five cases of maternal deaths, which underwent medico-legal autopsy during 1-1-1995 to April 2003 at Department of Forensic Medicine, Government Medical College, Thiruvananthapuram, Kerala were included after obtaining approval from Institutional Review Board. Maternal deaths due to pregnancy or within 42 days of termination of pregnancy, irrespective of duration and site of pregnancy are included. The factors that lead to medico-legal autopsy in maternal deaths were cases referred from peripheral hospitals, remote areas, as brought dead obstetric cases, allegation of negligence by the next of kin of the deceased regarding the management of pregnancy, delivery, and accidental and incidental cases. The objectives of medicolegal autopsy were strictly adhered to while conducting postmortem examination. Data for each case was collected by closed questionnaire prepared for this purpose. In all cases, clinical case records if available were perused. Post-mortem detailed notes of medico-legal autopsy in maternal death cases from 1-1-1995 to 2000 were perused retrospectively and entered in the proforma. Maternal death cases during the period from 2001 to April 2003 were studied prospectively. Relevant information from investigating officers, relatives of deceased and treatment records were also collected prior to autopsy.

During autopsy external features, post-mortem changes, injuries i.e. surgical and non-surgical, needle puncture marks, episiotomy wound, LSCS sutures etc. were carefully noted and recorded. All internal organs were inspected and dissected in detail. The abdominal and pelvic cavities were inspected to allow clear demonstration of an anatomy and injuries if any to pelvic vessel, broad ligament, uterus cervix and upper vagina. The placenta if present was also left attached to the uterine wall if possible. Site of attachment of placenta was recorded and the same was subjected to histopathology study to find out retroplacental haemorrhages and infarction, retained products of conception, placenta accreta, increta, percreta, couvelaire uterus etc. Histopathology study of all organs, chemical examination of viscera, blood and urine, and swab from infected lesions were sent for microbiology examination.

The collected data were subjected to analysis using Statistical Package for Social Sciences (SPSS).

\section{RESULTS}

Sixty five cases of maternal deaths, which underwent medicolegal autopsy during 1995 to April 2003 were analysed. The year wise break-up of cases and their percentages are given in Table 1. Highest number of cases were during 2001 thirteen cases (20\%) and least in 1995 five cases (7.9\%).

\begin{tabular}{|c|c|c|}
\hline Year & Maternal Death Cases & Percentage \\
\hline 1995 & 5 & 7.9 \\
\hline 1996 & 9 & 13.84 \\
\hline 1997 & 8 & 12.30 \\
\hline 1998 & 6 & 9.23 \\
\hline 1999 & 5 & 7.90 \\
\hline 2000 & 10 & 15.38 \\
\hline 2001 & 13 & 20.00 \\
\hline 2002 & 6 & 9.23 \\
\hline 2003 Jan - April & 3 & 4.8 \\
\hline Total & 65 & 100 \\
\hline \multicolumn{3}{|c|}{$\begin{array}{c}\text { Table 1. Year Wise distribution and Percentage of } \\
\text { Maternal Deaths }\end{array}$} \\
\hline
\end{tabular}

\begin{tabular}{|c|c|c|}
\hline Age Group & Number of Cases & Percentage \\
\hline$<20$ & 2 & 3.1 \\
\hline $20-24$ & 16 & 23.1 \\
\hline $25-29$ & 31 & 47.7 \\
\hline $30-34$ & 11 & 16.9 \\
\hline$>35$ & 6 & 9.2 \\
\hline Total & $\mathbf{6 5}$ & $\mathbf{1 0 0}$ \\
\hline \multicolumn{2}{|c|}{ Table 2. The Age Wise distribution of Maternal Deaths } \\
\hline
\end{tabular}

\begin{tabular}{|rr|c|c|}
\hline \multicolumn{2}{|c|}{ Phase of Pregnancy } & Number of Cases & Percentage \\
\hline 1. & Ante-natal & 27 & 41.5 \\
\hline 2. & Intra-natal & 04 & 06.2 \\
\hline 3. & Post-natal & 32 & 49.2 \\
\hline $4 . \quad$ Post-abortal & 02 & 03.1 \\
\hline \multicolumn{4}{|c|}{$\begin{array}{c}\text { Table 3. Distribution of Maternal Deaths based on Phase of } \\
\text { Pregnancy }\end{array}$} \\
\hline
\end{tabular}

\begin{tabular}{|c|c|c|}
\hline Causes & Number of Cases & Percentage \\
\hline Direct maternal deaths & 39 & 60 \\
\hline Indirect maternal deaths & 24 & 37 \\
\hline Undetected deaths & 02 & 3 \\
\hline
\end{tabular}




\begin{tabular}{|c|c|c|c|}
\hline Sl. No. & Causes & n & Percentage \\
\hline 1 & Heart Diseases & 7 & 10.8 \\
\hline 2 & Hypoxic Encephalopathy & 5 & 7.7 \\
\hline 3 & Hepatitis & 3 & 4.6 \\
\hline 4 & Intracranial Haemorrhage & 3 & 4.6 \\
\hline 5 & Tuberculosis & 2 & 3.1 \\
\hline 6 & Obstructive Airway Disease & 1 & 1.6 \\
\hline 7 & Adrenal Insufficiency & 1 & 1.6 \\
\hline 8 & Acute Renal Failure & 1 & 1.6 \\
\hline 9 & $\begin{array}{c}\text { Acute Respiratory Distress } \\
\text { Syndrome }\end{array}$ & 1 & 1.6 \\
\hline & Total & $\mathbf{2 4}$ & $\mathbf{3 6 . 9 2} \mathbf{3 7 \% )}$ \\
\hline
\end{tabular}

Table 5. Causes of Indirect Maternal Deaths and their Percentage

\begin{tabular}{|c|c|c|c|}
\hline $\begin{array}{l}\text { Sl. } \\
\text { No. }\end{array}$ & Type of Heart Disease & $\mathbf{n}$ & $\%$ \\
\hline 1 & $\begin{array}{l}\text { Rheumatic heart disease with mitral } \\
\text { stenosis }\end{array}$ & 2 & 3.1 \\
\hline 2 & Myocarditis & 2 & 3.1 \\
\hline 3 & $\begin{array}{c}\text { Rheumatic heart disease with aortic } \\
\text { stenosis }\end{array}$ & 1 & 1.6 \\
\hline 4 & $\begin{array}{c}\text { Mitral regurgitation with pulmonary and } \\
\text { Tricuspid regurgitation }\end{array}$ & 1 & 1.6 \\
\hline \multirow[t]{2}{*}{5} & Atrial septal defect & 1 & 1.6 \\
\hline & Total & 7 & $11 \%$ \\
\hline \multicolumn{4}{|c|}{$\begin{array}{c}\text { Table 6. Type of Heart Disease as indirect cause of } \\
\text { Maternal Death }\end{array}$} \\
\hline
\end{tabular}

(Results expressed as percentage).

\begin{tabular}{|c|c|c|c|c|}
\hline Author & $\begin{array}{c}\text { Period of } \\
\text { Study }\end{array}$ & $\begin{array}{c}\text { Direct } \\
\text { Causes }\end{array}$ & $\begin{array}{c}\text { Indirect } \\
\text { Causes }\end{array}$ & $\begin{array}{c}\text { Coincidental } \\
\text { Causes }\end{array}$ \\
\hline Kavatkar et al $^{5}$ & $1993-2000$ & 49.5 & 34.7 & 15.8 \\
\hline $\begin{array}{c}\text { Panchabhai } \\
\text { etal }^{6}\end{array}$ & $1998-2006$ & 48.3 & 51.7 & --- \\
\hline Kulkarni et al $^{7}$ & $2009-2014$ & 73.11 & 24.84 & 02 \\
\hline Vasaikar et al $^{8}$ & $2008-2012$ & 50.9 & 47.3 & 01.8 \\
\hline $\begin{array}{c}\text { Jashnani K.D, } \\
\text { Rupani AB, } \\
\text { Wani RJ }\end{array}$ & $2003-2007$ & 38.2 & 53.93 & 07.8 \\
\hline $\begin{array}{c}\text { Present study } \\
\text { Presen }\end{array}$ & $\begin{array}{c}1995- \\
\text { 2003 }\end{array}$ & 60 & 37 & 03 \\
\hline \multicolumn{5}{|c|}{ Table 7. Comparison with Similar Studies in India } \\
regarding Maternal Deaths \\
\hline
\end{tabular}

(Results expressed as percentage).

\begin{tabular}{|c|c|c|c|c|}
\hline Author & $\begin{array}{c}\text { Period of } \\
\text { Study }\end{array}$ & $\begin{array}{c}\text { Direct } \\
\text { Causes }\end{array}$ & $\begin{array}{c}\text { Indirect } \\
\text { Causes }\end{array}$ & $\begin{array}{c}\text { Coincidental } \\
\text { Causes }\end{array}$ \\
\hline $\begin{array}{c}\text { De Lean Ponce } \\
\text { et al10 }\end{array}$ & $1973-2013$ & 86.9 & 13.1 & - \\
\hline $\begin{array}{c}\text { Say L, Chou D } \\
\text { Gemmill et al11 }\end{array}$ & $2003-2009$ & 72.5 & 27.5 & ---- \\
\hline $\begin{array}{c}\text { Yoneyama et } \\
\text { al12 }\end{array}$ & $1984-2014$ & 73.1 & 26.9 & ----- \\
\hline $\begin{array}{c}\text { Der EM, Adu- } \\
\text { Bonsaffoh et } \\
\text { al13 }\end{array}$ & $1995-2014$ & 84.8 & 15.2 & ------ \\
\hline $\begin{array}{c}\text { Present study } \\
\text { Table 8. Comparison with similar studies abroad } \\
\text { regarding Maternal Deaths }\end{array}$ \\
\hline \multicolumn{4}{|c|}{ Tag- } \\
\hline
\end{tabular}

\section{DISCUSSION}

Maximum number of maternal deaths were in the age group between 25 - 29 years 31 cases $(47.7 \%)$ and minimum number below 20 years 2 cases (3.1\%). The eldest mother in the study group was 48 years and youngest 18 years old. The age wise distribution of maternal death is shown in Table No. 2.

Thirty eight maternal deaths were primigravida (58.5\%), 22 cases were second gravida (33.8\%) and there was one fifth gravida. There was no history of abortion in $94 \%$ cases and $6.2 \%$ cases had previous history of abortion. Of the maternal deaths analysed, 58 cases i.e. 90\% had normal conception and the 7 cases were ectopic pregnancy $(10.7 \%)$. Based on the phase of pregnancy they were categorised into antenatal, intranatal, postnatal and post-aborted deaths. Maximum maternal deaths were during the postnatal phase 32 cases, which accounted for $49 \%$. The accompanying Table3 show the distribution of cases based on the phase of pregnancy.

Analysing the type of delivery, maximum maternal deaths i.e. 24 cases $(38.5 \%)$ were following caesarean section and its complications followed by $12(18.5 \%)$ cases of normal delivery.

Among the causes, direct maternal deaths were attributed in 39 cases $(60 \%)$. Non-obstetric causes of maternal deaths observed were indirect deaths in 24 cases (36.9\%), no definite causes could be attributed in 2 cases (3\%), there were no late deaths. Causes of maternal deaths and their percentage are shown in Table No. 4.

Fortuitous deaths were also categorised as non-obstetric causes in the present study. In 1995 there were 17 and in 2001 there were 9 deaths. These deaths were mainly unnatural deaths, their maternal age and cause of death were given in the following Table No. 5 .

Indirect causes of maternal deaths could be attributed in 24 cases, i.e. $37 \%$. Cardiovascular pathology was the leading cause of death during pregnancy in 7 cases $(10.8 \%)$, hypoxic encephalopathy following anaesthesia complicating pregnancy were next in 5 cases $(7.7 \%)$ followed by hepatitis, intracranial haemorrhages, 3 cases each (3.1\%), others included one case each $(1.6 \%)$ viz. obstructive airway disease, adrenal insufficiency, acute renal failure and acute respiratory distress syndrome.

Rheumatic valvular heart disease complicating pregnancy was the cause of death in five cases (7.7\%). Among them, there were three primigravida and one multigravida. In the primigravida, death occurred at first and eighth month and on the sixth day respectively following full-term normal delivery. In the lone multigravida death was due to multivalvular complications and also myocarditis as the terminal event. Atrial septal defect, a congenital heart disease complicating pregnancy was the cause of death in one case. Myocarditis was diagnosed in 2 cases (3.1\%), one was a primi following full-term normal delivery and the other a second gravida following caesarean section. In both cases, the cause of death was confirmed by histopathology. Microscopy revealed increased waviness of myocardial fibres, eosinophilia, focal collection of plasma cell, lymphocyte and occasional polymorphs. The various cardiovascular causes contributing to the indirect causes are summarised in the following Table 6 . 
Hypoxic encephalopathy was another leading cause 5 cases (7.7\%), among them two were primi and another was a second gravida who underwent caesarean section and hypoxic encephalopathy developed on fifth post-operative day. There was history of obstructed labour in the other two cases of encephalopathy. All cases showed subendocardial haemorrhages. Lignocaine drug was detected in the viscera and blood in one case, three days following caesarean section. There was evidence of raised intracranial tension, pulmonary oedema and focal infiltration of heart muscle with neutrophils.

Hepatitis and intracranial haemorrhages accounted for 2 cases each $(3.1 \%)$ of indirect deaths. Hepatitis manifested as specific, active hepatitis and ischaemic necrosis of liver. Deaths due to intracranial haemorrhages were the indirect causes of death in three primigravidae. In the above cases death occurred during first, fifth and sixth month of pregnancy respectively. The site of bleeding were at basal ganglia in two cases. In another case there was bleeding with softening and necrosis of thalamus and in the third case subarachnoid haemorrhage due to rupture of berry aneurysm at left middle cerebral artery. In the above case, the cerebral vessels and aorta were rubbery in consistency with ulceration, calcified plaques and mononuclear infiltration suggestive of lytic infection.

Tuberculosis was the cause of death in two primigravidae, one was affected by pulmonary and another affected by miliary tuberculosis. In the primi affected by pulmonary tuberculosis death occurred at $8^{\text {th }}$ month and in those case with miliary tuberculosis at $3^{\text {rd }}$ month of pregnancy. Miliary tuberculosis was complicated by atypical pneumonia, endometrium of uterus showed dilated gland lined by cuboidal cell, nuclear atypia, inflammatory cell infiltrate with lymphocyte plasma cell, histiocyte and giant cells associated with multiple granulomatous lesion in liver, spleen, uterus, ovary and lung.

Obstructive airway disease was the cause of death in one case at full term. Lungs showed emphysematous change. Adrenal insufficiency was the cause of death in a primigravida. Adrenal showed whitish nodules on its surface with nodular hyperplasia. Acute renal failure was the cause of death in a second gravida following caesarean section. Death occurred two days after operation. Acute respiratory distress syndrome was seen in a second gravida following caesarean section. Lungs showed partial collapse, congestion, oedema and thickened alveolar septa.

Fortuitous death in a five-year interval, i.e. accidental or unnatural deaths, that is in 1995 and 2001 were analysed. In 1995 there were 17 and in 2001 there were 9 deaths. Maximum deaths were in 20 to 24 years' age group. The cause of deaths were mostly hanging, burns, drowning and poisoning and the manner were mostly suicide. During 2001 there was a case of ligature strangulation, the victim was an unmarried 19-year-old girl and a case of head injury following road traffic accident.

Comprehensive analysis of the causes of maternal mortality has been published by WHO and the Institute for Health Metrics and Evaluation. These analyses strikingly show the increasing importance of indirect causes of maternal deaths. Say and colleagues noted that $27.5 \%$ of all maternal deaths result from indirect causes with the highest proportion of such deaths in South Asia and Sub-Saharan Africa. ${ }^{11}$

A retrospective analysis of 7735 maternal deaths during forty-year period 1973 to 2013 occurred in six Mexican intensive care units. From the total deaths, 6723 were direct causes and 1012 were indirect causes. Out of $75 \%$ of total indirect causes cardiopathy (42\%), endocrinopathy (15\%), pneumopathy $(10 \%)$, gastropathy and nephropathy $(8 \%)$ blood disorder $(6 \%)$, rheumatic disease $(4 \%)$, anaesthesia (3\%), anaphylaxis (2\%) and trauma (2\%). ${ }^{10}$

In the triennium 2011 - 2013, 214 women in the UK died directly or indirectly related to pregnancy. Cardiac disease was the most common cause of indirect death. The indirect maternal mortality rate has not changed significantly since 2003 , it is 6.11 per one lakh maternities. The indirect causes of death rate per one lakh mortalities were as follows: cardiac (2.06) indirect causes- influenza, pneumonia and others (1.26), indirect neurological conditions including epilepsy (1.01), psychiatric (0.80) and late maternal deaths (14.12). ${ }^{14}$

Regarding indirect causes, a retrospective analysis on 144 pregnancies in women with cardiac disease who delivered in a single centre in Turkey showed that rheumatic (87.5\%) and congenital heart disease (12.5\%) were the only causes of disease with $44.4 \%$ of patients presenting in New York Heart Association Classes II and IV. Data from Iran revealed a maternal mortality rate of $4.0 \%(n=8)$ with pregnant women with congenital heart disease experiencing higher mortality rates. In low-to-middle income countries, rheumatic heart disease contributes to $30 \%$ of cardiovascular disease seen in pregnancy and remains an important determinant of morbidity and mortality. Rheumatic valvular lesions were the commonest abnormalities found in South Africa where the most frequent complications were pulmonary oedema, thromboembolism and major bleeding related to warfarin use. Yoneyama et al studied the clinical characteristic of pregnancy associated maternal deaths in obstetrics and gynaecology of Nippon Medical School, Japan from January first 1984 to December 31 ${ }^{\text {st }}$ 2014. It was a retrospective analysis with medical record and autopsy report of cases of pregnancy associated deaths. Total 26 maternal deaths occurred during 31 years study period. Autopsy was performed on 16 patients $(61.5 \%)$ The 26 cases of death included 19 (73.1\%) classified as direct maternal deaths and $7(26.9 \%)$ as indirect maternal deaths. Mean age was $33.1^{+}$ 4.3. In cases of indirect obstetric deaths, causes were cardiovascular which included primary pulmonary hypertension, dissecting aneurysm with Marfan's syndrome, sepsis due to Group A streptococci and hepatic failure. ${ }^{12}$

Maternal mortality, an autopsy audit conducted at BYL Ch. Hospital, Central Mumbai, 89 autopsies of maternal deaths during 2003 to 2007 were conducted and studied along with clinical details. Of the 89 autopsies, acute fulminant viral hepatitis was the commonest cause of indirect maternal deaths (37 cases, $41.5 \%$ ) followed by anaemia and sickle cell disease ( 5 cases, $5.6 \%$ ), cerebral malaria (3 cases, $3.3 \%$ ), cardiac ( 2 cases, $2.2 \%$ ) and essential hypertension ( 1 case, $1.1 \%) .^{9}$

Comparison of percentage of indirect maternal deaths with similar studies done in other countries are summarised in Table No. 8. 


\section{CONCLUSION}

Maternal mortality rates are an index of the state of a nation's health system. Maternal autopsies help to determine these rates, provide information on avoidable/ unavoidable causes of mortality, consequently leading to the development of strategies for treatment and prevention of maternal mortality and morbidity.

Sixty five maternal deaths brought for medico-legal autopsy to Department of Forensic Medicine, Govt. Medical College, Thiruvananthapuram, during 1995 to 2003 April were included in this study. In majority of cases, autopsy examination was conducted due to allegation of medical negligence against doctors and hospital authorities for lack of adequate obstetric care. More than $80 \%$ cases were referred cases from peripheral health care centres, either in terminal stage to the tertiary centre and as brought dead cases.

- Maximum number of maternal deaths were in 2001 and 2002. During the above period, there were ten and thirteen maternal deaths brought for autopsy respectively.

- $\quad$ The predominant maternal age was between 25 - 29 years $(47.7 \%)$ and 38 cases were primigravida (58.5\%).

- Direct maternal deaths were the leading cause (39 cases, $60 \%$ ) followed by indirect deaths (24 cases, $36.9 \%$ ) and undetermined (2 cases, 3.1\%).

- The leading indirect cause of maternal death was attributed to cardiovascular pathology (11\%), rheumatic heart disease with valve involvement was the major cause.

- Cardiovascular cause as a major determinant of indirect maternal death was observed in similar studies cited above.

- Early detection, diagnosis, management and preventive measures taken during reproductive age can prevent cardiovascular causes of maternal deaths in high risk mothers.

Maternal death is a measure of quality of health care in a community. Though the risk of death from complications of pregnancy has decreased during the past few decades in India, it continues to remain higher in developing countries.

Regular death audit meetings and mortality conferences including obstetricians, forensic pathologist, pathologist, anaesthetists at institutional level create awareness regarding causes and avoidability of the maternal deaths.

The lesson from post-mortem examinations using the vehicle of confidential enquiries into maternal deaths can save the lives of many, causing reduction in both maternal and perinatal mortality as well as reductions in morbidity. ${ }^{15}$ However, for autopsies to fulfil this role they must be of a very high standard and must be subjected to quality control measures. Encouraging hospital autopsy with histopathology and microbiology examination in all maternal deaths will help in understanding the cause of death, particularly preventable ones.

\section{REFERENCES}

[1] World Health Organization, Regional Office for South East Asia. Maternal Health in South East Asia Region 2015. New Delhi, India: WHO, 2015.

[2] Rhuston DI. Maternal autopsy, hospital autopsy. New Delhi, India: Jaypee Brothers 1994;9: p. 117.

[3] niti.gov.in/content/maternal-mortality-ratio-mmr100000-live-births.

[4] Paily VP, Ambujam K, Nair RV, et al. Confidential review of maternal deaths in Kerala: a country case study. BIOG 2014;121(Suppl 4):61-6.

[5] Kavatkar AN, Sahasrabudhe NS, Jadhav MV, et al. Autopsy study of maternal deaths. Int Journal Gynaecol Obstet 2003;81(1):1-8.

[6] Panchabhai TS, Patil PD, Shah DR, et al. An autopsy study of maternal mortality: a tertiary healthcare perspective. J Postgrad Med 2009;55(1):8-11.

[7] Kulkarni AM, Chaudhari AA, Jadhav NS, et al. Clinicopathological co-relation of maternal deaths in a tertiary care centre, Southern Maharashtra. Nat J Community Med 2016;7(4):343-7.

[8] Vasaikar MS, Kanthikar SN, Tambse MP. Clinicopathological correlation of maternal death in rural areas of North Maharashtra. Int J Pharm Bio Sci 2014;5(1):(B)449-56.

[9] Jashnani KD, Rupani AB, Wani RJ. Maternal mortality: an autopsy audit. Journal of Postgraduate Medicine 2009;55(1):12-6.

[10] De Ponce LMAD, Carlos BGJ, Alberto MSA. The problem of indirect causes of maternal mortality. Journal of Pregnancy and Child Health 2015;2(1):126. http//dx doi.org/10 4172/2376-127x.1000126

[11] Say L, Chou D, Gemmill A, et al. Global causes of maternal death: a WHO systematic analysis. Lancet Global Health 2014;2(6):e323-e33.

[12] Yoneyama K, Sekiguchi A, Matsushima T, et al. Pregnancy-associated deaths: 31-year experience. Journal of Nippon Medical School 2016;83(1):6-14.

[13] Der EM, Adu-Bonsaffoh K, Kwame-Aryee RA, et al. Indirect obstetric causes of maternal deaths: a twentyyear retrospective study at the Korle- $\mathrm{Bu}$ teaching hospital. Postgraduate Medical Journal of Ghana 2017;6(1):34-41.

[14] Patient.info/doctor/maternal mortality

[15] Bardale RV, Dixit PG. Pregnancy related deaths: a three year retrospective study. Journal of Indian Academy of Forensic Medicine 2010;32(1):15-8. 